\section{Tissue microarray construction from bone marrow biopsies}

\author{
Ellen C. Obermann ${ }^{1}$, Joerg Marienhagen ${ }^{1}$, Robert Stoehr ${ }^{1}$, \\ Peter $\mathrm{H}$. Wuensch ${ }^{2}$, and Ferdinand Hofstaedter ${ }^{1}$ \\ ${ }^{1}$ University of Regensburg, Regensburg and ${ }^{2}$ Clinical Center Nuremberg, Nuremberg, \\ Germany
}

BioTechniques 39:822-826 (December 2005)

doi $10.2144 / 000112073$

Tissue microarray (TMA) methodology has accelerated tissue analysis by in situ technologies. This technology allows rapid evaluation of large numbers of tissue samples (1-4). In this technique, small tissue samples are taken from tissue blocks containing routinely processed specimens and inserted into a recipient block that may contain up to 1000 specimens (5). Any antibody staining, in situ hybridization, and other molecular detection technology, which is applicable to whole tissue sections, can also be adapted to TMA slides (6). However, TMAs have, so far, mostly been made from paraffin-embedded tissue samples in which the original block contained relatively large specimens. It has been said that "it is not a major problem for a skilled technician to produce tissue microarrays from decalcified bone marrow biopsies" (7), but as yet, no study has been published proving the applicability of this method.

Availability of TMAs from bone marrow biopsies (BMBs) would be especially useful in hematopathologic research, because a large number of neoplasms of the lymphatic and hematopoietic system involve the bone marrow. In some entities, such as leukemia, BMBs can be the only type of tissue containing neoplastic cells that is available for the histopathologist. The high-throughput, time- and costefficient TMA technology is therefore highly desirable to facilitate research in this field.

There are several draw backs when dealing with BMBs. The major challenge is that the average BMB is not more than $2.0 \mathrm{~mm}$ wide and $2.5 \mathrm{~cm}$ long; however, a thickness of the donor tissue of 3-4 mm is usually required for TMA construction (6).

Therefore, we modified the conventional technique of constructing TMAs and adjusted it to the special requirements of BMBs. Basically, we followed the protocol for manufacturing TMAs as described previously (8) and modified it according to the needs of the material used. Briefly, routinely processed BMBs were retrieved from the archives of the Institutes of Pathology at the University of Regensburg and the Clinical Center of Nuremberg. Areas of interest were marked on the original hematoxylin and eosin (H\&E)-stained slide. Biopsies were taken from the preselected areas in the original blocks and inserted into premade holes in the acceptor block at defined array coordinates using a specially manufactured stainless steel tube with a wall thickness of $0.1 \mathrm{~mm}$ and a diameter of 1.6 $\mathrm{mm}$ (Sueddeutsche Feinmechanik GmbH, Waechtersbach, Germany). This size had been found to give the best results regarding preservation of the punch biopsy. Most importantly, instead of inserting the tissue samples next to each other in different holes in the donor block, as it is usually done, we stacked up to three punch biopsies obtained biopsy from one donor block on top of each other into one single hole in the acceptor block (Figure 1). Using this "stack method" a final thickness of tissue in the donor block of up to $4 \mathrm{~mm}$ can be achieved. Equal thickness of almost all the samples in a TMA block is especially desirable, since it avoids the well-known problem of cores being not yet or not any more cut from a TMA (9). However, a minor "loss of tissue" might be observed in sections between individual stacks.

Despite the small size of the samples, it was still possible in most cases to construct three cores from the same case in the final TMA; this is desirable because additional cores of identical cases increase the agreement in results between conventional sections and TMA (10). So far, we have successfully constructed four TMAs from BMBs, altogether containing 75 cases.

In order to prove the validity of the stack method, we assessed the expression of several cell cycle markers by immunohistochemistry-both in whole tissue samples and in the core biopsies in one of our newly constructed TMAs containing 33 core biopsies from 11 cases of chronic lymphocytic leukemia (CLL) (Figure 2).

Whole sections from the donor blocks before construction of the microarray and sections from the final microarrays were stained for $\mathrm{Ki}-67$ (mouse monoclonal, clone MIB1; DAKO, Hamburg, Germany; final dilution 1:50), BM28 for detection of

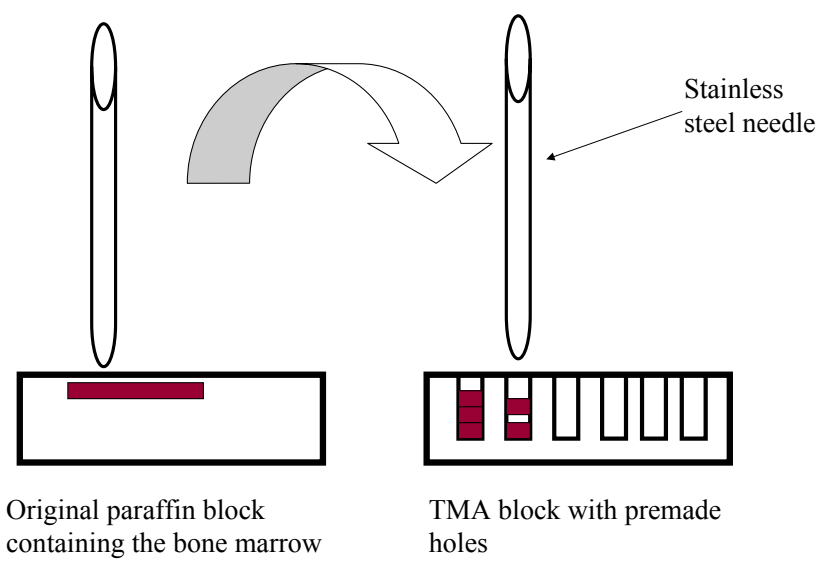

Figure 1. Construction of a tissue microarray (TMA) using the stack method. Core biopsies are punched from the original paraffin block (left) using a stainless steel needle and put on top of each other into premade holes in the TMA block (right). 
Mcm2 (mouse monoclonal, clone 46; BD Biosciences, San Jose, CA, USA; final dilution 1:3000), and Cyclin $\mathrm{E}$ (mouse monoclonal, clone 13A3; NovoCastra, Newcastle, UK; final dilution 1:5) using standard procedures with heat-induced antigen retrieval (microwave for $30 \mathrm{~min}$ at $320 \mathrm{~W}$ ) and visualization of staining by the avidinbiotin peroxidase method with diaminobenzidine chromatogen.

$\mathrm{Ki}-67$ was chosen because it is the standard proliferation marker in histopathological research (11), while Mcm2 denotes the proliferative potential of
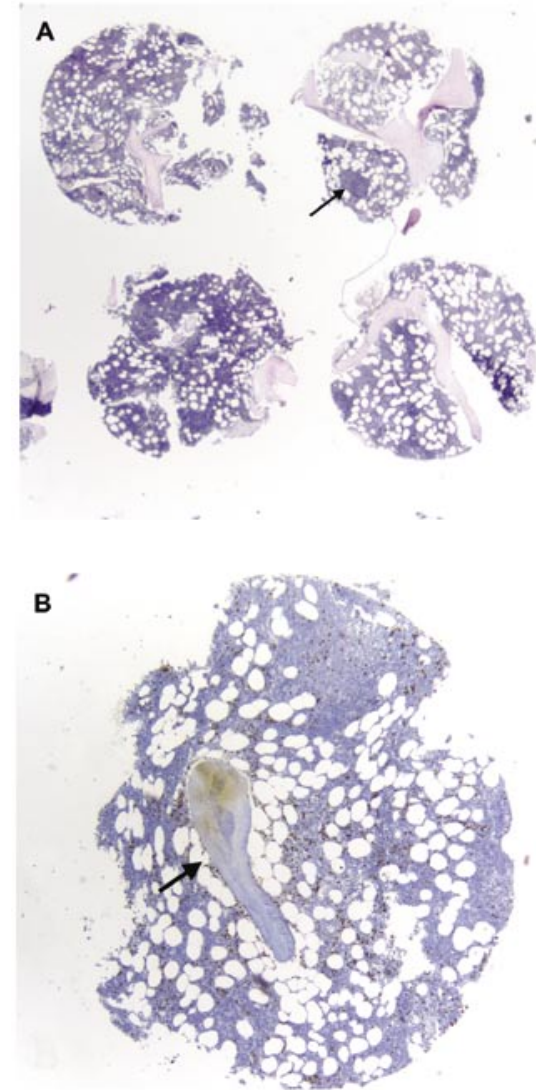

Figure 2. Tissue microarrays (TMAs) constructed from bone marrow biopsies (BMBs) utilizing the stack method. This TMA contains 33 cores of 11 BMBs infiltrated by chronic lymphocytic leukemia (CLL). (A) This overview of a hematoxylin and eosin (H\&E)-stained slide shows four core biopsies. The architecture of both marrow and bone structures are well preserved. Cellularity and the distribution of cells can easily be appreciated. A nodular infiltrate by CLL is clearly recognizable (arrow). (B) This close-up view of a core biopsy stained for the proliferation marker Ki-67 shows distribution of fat cells and hematopoietic/lymphatic cells. There is excellent preservation of the bone trabecula (arrow). cells and has been exploited as a novel marker of tumor growth (12). Cyclin $\mathrm{E}$ overexpression has been reported in several neoplasms including hematological neoplasias (13). Therefore, these markers are likely to be used in further studies utilizing TMAs of BMBs.

One hundred cells were assessed in both whole sections and tumor cores, and the labeling index (LI) for each protein (percentage of cells with a distinct nuclear staining) was calculated. If more than one core biopsy was available from the same case, the results were averaged. Statistical analyses were performed using SPSS version 10.0 (SPSS, Chicago, IL, USA). Evaluation of immunohistochemical staining was possible in 96 of 99 (97\%) core biopsies. Noninformative cases were attributable to the array technology (i.e., loss of tissue) (9). However, more than one core biopsy of the same BMB was available in these cases. The comparison of LIs for both whole section and core biopsies showed correlations for all markers (intraclass correlation coefficient: 0.881 for Ki-67, 0.619 for $\mathrm{Mcm} 2$, and 0.858 for Cyclin $\mathrm{E})$, which were all significant $(P$ values: $<0.001$ for Ki-67, 0.013 for Mcm2, and $<0.001$ for Cyclin E).

In summary, we show that construction of a TMA from BMBs is possible using the stack method and prove the validity of our approach by comparing immunohistochemical results obtained from whole tissue sections and core biopsies. This method can easily be performed by anyone experienced in the construction of conventional TMAs. Furthermore, the stack method may be transferred to other fields of research where only small tissue samples, such as renal or liver biopsies, are available.

\section{ACKNOWLEDGMENTS}

The authors thank A. Vielberth and $R$. Jung for excellent technical assistance. This study was supported by a grant of the University of Regensburg to E.C.O. (Regensburger Forschungsförderung in der Medizin: ReForM A).

\section{COMPETING INTERESTS STATEMENT}

The authors declare no competing interests.

\section{REFERENCES}

1. Bubendorf, L., J. Kononen, P. Koivisto, P. Schraml, H. Moch, T.C. Gasser, N. Willi, M.J. Mihatsch, et al. 1999. Survey of gene amplifications during prostate cancer progression by high-throughout fluorescence in situ hybridization on tissue microarrays. Cancer Res. 59:803-806.

2. Kononen, J., L. Bubendorf, A. Kallioniemi, M. Barlund, P. Schraml, S. Leighton, J. Torhorst, M.J. Mihatsch, et al. 1998. Tissue microarrays for high-throughput molecular profiling of tumor specimens. Nat. Med. 4:844-847.

3. Barlund, M., F. Forozan, J. Kononen, L. Bubendorf, Y. Chen, M.L. Bittner, J. Torhorst, P. Haas, et al. 2000. Detecting activation of ribosomal protein S6 kinase by complementary DNA and tissue microarray analysis. J. Natl. Cancer Inst. 92:1252-1259.

4. Bubendorf, L., M. Kolmer, J. Kononen, P. Koivisto, S. Mousses, Y. Chen, E. Mahlamaki, P. Schraml, et al. 1999. Hormone therapy failure in human prostate cancer: analysis by complementary DNA and tissue microarrays. J. Natl. Cancer Inst. 91:1758-1764.

5. Bubendorf, L., A. Nocito, H. Moch, and G. Sauter. 2001. Tissue microarray (TMA) technology: miniaturized pathology archives for high-throughput in situ studies. J. Pathol. 195:72-79.

6. Kallioniemi, O.P., U. Wagner, J. Kononen, and G. Sauter. 2001. Tissue microarray technology for high-throughput molecular profiling of cancer. Hum. Mol. Genet. 10:657-662.

7.Packeisen, J., E. Korsching, H. Herbst, W. Boecker, and H. Buerger. 2003. Demystified...tissue microarray technology. Mol. Pathol. 56:198-204.

8. Tzankov, A., A. Zimpfer, A.C. Pehrs, A. Lugli, P. Went, R. Maurer, S. Pileri, and S. Dirnhofer. 2003. Expression of B-cell markers in classical hodgkin lymphoma: a tissue microarray analysis of 330 cases. Mod. Pathol. 16:1141-1147.

9. Mengel, M., H. Kreipe, and R. Von Wasielewski. 2003. Rapid and large-scale transition of new tumor biomarkers to clinical biopsy material by innovative tissue microarray systems. Appl. Immunohistochem. Mol. Morphol. 11:261-268.

10.Camp, R.L., L.A. Charette, and D.L. Rimm. 2000. Validation of tissue microarray technology in breast carcinoma. Lab. Invest. 80:1943-1949.

11.Endl, E., C. Hollmann, and J. Gerdes. 2001 Antibodies against the $\mathrm{Ki}-67$ protein: assessment of the growth fraction and tools for cell cycle analysis. Methods Cell Biol. 63:399418. 


\section{BENCHMARKS}

12.Stoeber, K., T.D. Tlsty, L. Happerfield, G.A. Thomas, S. Romanov, L. Bobrow, E.D. Williams, and G.H. Williams. 2001. DNA replication licensing and human cell proliferation. J. Cell Sci. 114:2027-2041.

13.Schraml, P., C. Bucher, H. Bissig, A. Nocito, P. Haas, K. Wilber, S. Seelig, J. Kononen, et al. 2003. Cyclin E overexpression and amplification in human tumours. J. Pathol. 200:375382

Received 15 September 2005; accepted 17 October 2005.

Address correspondence to Ellen $C$. Obermann, Institute of Pathology, University of Regensburg, Franz-JosefStrauss-Allee 11, 93053 Regensburg, Germany.e-mail: ellen.obermann@klinik. uni-regensburg.de

To purchase reprints

of this article, contact

Reprints@BioTechniques.com 